\title{
Implementation and validation of a coastal forecasting system for wind waves in the Mediterranean Sea
}

\author{
R. Inghilesi ${ }^{1}$, F. Catini ${ }^{2}$, G. Bellotti ${ }^{3}$, L. Franco ${ }^{3}$, A. Orasi ${ }^{1}$, and S. Corsini ${ }^{1, *}$ \\ ${ }^{1}$ ISPRA, Istituto Superiore per la Protezione e la Ricerca Ambientale, Roma, Italy \\ ${ }^{2}$ Consorzio per le Attività di Supercalcolo per Universita e Ricerca, Roma, Italy \\ ${ }^{3}$ Dipartimento di Scienze dell'Ingegneria Civile, Università Roma Tre, Roma, Italy \\ *now at: CIPE, Presidenza del Consiglio, Roma, Italy
}

Correspondence to: R. Inghilesi (roberto.inghilesi@isprambiente.it)

Received: 22 April 2011 - Revised: 14 December 2011 - Accepted: 3 January 2012 - Published: 29 February 2012

\begin{abstract}
A coastal forecasting system was implemented to provide wind wave forecasts over the whole Mediterranean Sea area, and with the added capability to focus on selected coastal areas. The goal of the system was to achieve a representation of the small-scale coastal processes influencing the propagation of waves towards the coasts. The system was based on a chain of nested wave models and adopted the WAve Model (WAM) to analyse the large-scale, deep-sea propagation of waves; and the Simulating WAves Nearshore (SWAN) to simulate waves in key coastal areas. Regional intermediate-scale WAM grids were introduced to bridge the gap between the large-scale and each coastal area. Even applying two consecutive nestings (Mediterranean grid $\rightarrow$ regional grid $\rightarrow$ coastal grid), a very high resolution was still required for the large scale WAM implementation in order to get a final resolution of about $400 \mathrm{~m}$ on the shores. In this study three regional areas in the Tyrrhenian Sea were selected, with a single coastal area embedded in each of them. The number of regional and coastal grids in the system could easily be modified without significantly affecting the efficiency of the system. The coastal system was tested in three Italian coastal regions in order to optimize the numerical parameters and to check the results in orographically complex zones for which wave records were available. Fifteen storm events in the period 2004-2009 were considered.
\end{abstract}

\section{Introduction}

The nature of the generation of wind waves and their propagation in time and space has been thoroughly investigated over recent decades. Although the understanding of the problem is still incomplete, the physical description of the spatial and temporal evolution of the wave spectra subject to the interactions with the atmosphere, sea currents and the sea bed is, today, a successful and established theory. As illustrated by Lavrenov (2003) and Janssen (2004), our knowledge of the interactions between atmosphere and ocean has significantly improved since the seminal papers of Phillips (1957) and Miles (1957). In particular, the use of the kinetic equation to describe the evolution of the wave spectrum (Komen et al., 1984) paved the way for the development of modern numerical methods for simulating the dynamics of wind waves. Over the last 30 years, wave modeling has been increasingly used in a variety of applications, from ocean forecasting to wave energy production and coastal management. A full discussion of the subject would be totally beyond the scope of the present work, but thorough accounts of the state of the art and the prospects for improvement of wave models can be found in Holthuijsen (2007), the WISE Group (2007) and Komen et al. (1994). Like many other geophysical phenomena, waves can be studied on very different space and temporal time scales (we refer to Sect. 1.7, Lavrenov, 2003, for a discussion of the relevant spatial and temporal scales for the physical processes associated with wind-waves). Ocean storms belong to large scales and are mainly related to the processes of wind momentum transfer, nonlinear transfer, current refraction and turbulent dissipation of energy. As waves move toward the shoreline other, physical processes become important, viz. refraction induced by sudden variations in depth (or by coastal currents) and shoaling. Since the forcings now become increasingly dependent on regional currents and local variations in bathymetry, the scale of the problem becomes smaller. In most situations the two types of waves can still be analyzed within the framework of the same theory. As a result, a third generation wave model like WAM, which efficiently solves the kinetic equation and the source functions in order to give global and regional forecasts, can 
be combined with other models like SWAN that are more oriented towards propagation on the coastal scale. We refer to Komen et al. (1994) and Janssen (2008) for a complete description of WAM, and to Booij et al. (1999) and The SWAN Team (1993) for information on SWAN. Given recent advances in the availability of computer power, it has become feasible to use chains of numerical models in order to connect the wave propagation from the large to the regional/coastal scales. The resulting system might provide not only large-scale wave forecasts based on synoptic-scale wind and satellite data assimilation, but also a realistic ongoing description of the coastal processes in smaller regional areas. Studies focused on waves in the Mediterranean Sea (Bertotti and Cavaleri, 2009; Cavaleri and Sclavo, 2006; Bertotti and Cavaleri, 2006; Komen et al., 1994) are in agreement, arguing that due to the small scale geographical features of the region, wave numerical forecasts can only be accurate when waves and surface winds are defined with a resolution finer than $1 / 3$ of a degree at the minimum. On the other hand, as Bertotti and Cavaleri (2009) observed, improved resolution (in the meteorological model) does not automatically mean improved accuracy (in wind and wave forecasting), especially when the increase in wind resolution is obtained by the use of limited area models. A dimensional analysis of the spectral energy density in the case of fixed fetch can be used to estimate the relative error in significant wave height $\left(H_{\mathrm{s}}\right)$ in terms of relative error in wind speed $(U)$ (Polnikov et al., 2008) as $\frac{d H_{\mathrm{s}}}{H_{\mathrm{s}}}=\frac{d U}{U}$. Consequently, in deep waters the accuracy of wave forecasts is largely dependent on the accuracy of the wind fields at the surface, which, in turn, is not simply dependent upon the resolution of the meteorological model. In coastal areas, the spatial resolution of the wave model should instead be sufficiently high to take into account the refraction due to spatial variations in currents and bathymetry. In the present study a resolution of $1 / 240$ degrees in the coastal areas was considered adequate. The resolution of the Mediterranean scale model and the regional intermediate models was chosen so as to have nesting scale ratios between two and four.

\section{The Mediterranean coastal forecasting system}

The Mediterranean Coastal Forecasting System (MCFS) is part of an integrated system of measurement networks and numerical modeling tools aimed at the monitoring of marine and coastal processes. Besides numerical waves prediction, the Italian Institute for Environmental Research and Protection (ISPRA) runs two real-time national marine networks: the National Waves Network (RON), and the National Tidegauges Network (RMN). The RON operates 15 deep water directional wave buoys, while the RMN manages 34 coastal stations equipped with meteorological instruments and tide gauges. For operational forecasts, the ISPRA Hydro-Marine and Meteorological Forecasting System (SIMM) provides

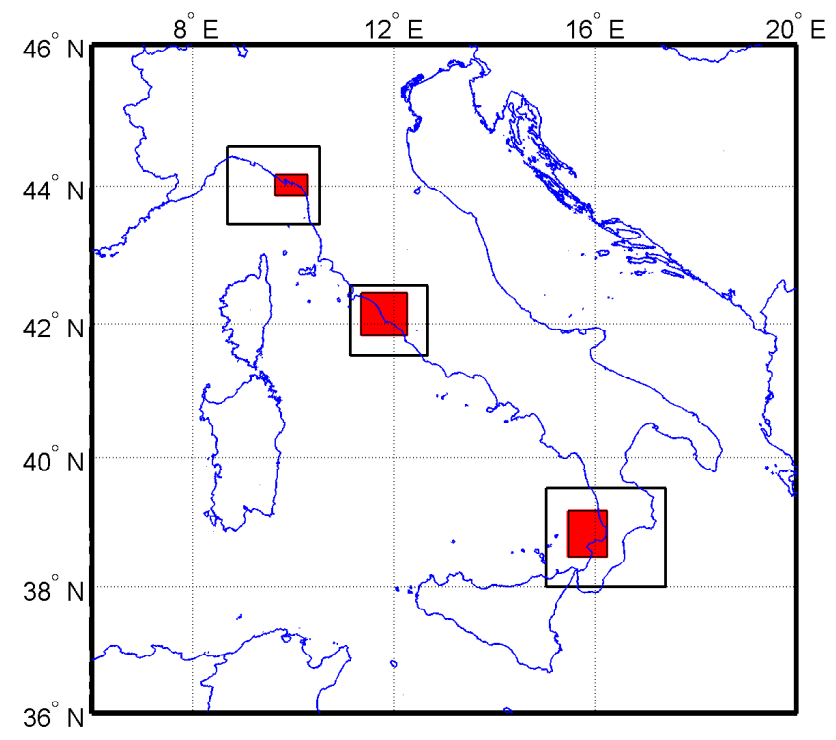

Fig. 1. Regional (black boxes) and coastal areas (red boxes) nested in the Mediterranean Sea grid.

short term ( 2 days) meteorological forecasts for the Mediterranean Sea area with 0.1/0.1 degrees Lat./Lon. resolution. The meteorological model used is the BOlogna Limited Area Model, or BOLAM (Lagouvardos et al., 2003; Buzzi et al., 1994). The SIMM has been operational since 2000 and underwent an upgrade of its meteorological modules in 2010 and 2011. Mediterranean Sea scale MCFS simulations are obtained by running the WAM model forced by the 3-hr time step wind field produced by BOLAM. The same wind field, at $0.1 / 0.1 \mathrm{deg}$. resolution, is also used for the regional and coastal areas. The wind fields are interpolated on the different grids by means of a remapping procedure in order to limit the smoothing due to bilinear interpolation (Accadia et al., 2002). The aim of the MCFS is not only to provide shortterm wave forecasts, but also to determine wave climates in shallow water so as to be able evaluate the effects of significant storms on coastal areas. The system first connects the global Mediterranean scale to the regional scale with a smooth nesting (nesting scale factor $1 / 2$ ), then in the regional areas it zooms on the local/coastal scale with a nesting scale factor 1/4. The large-scale part of the MCFS is based on the WAM cycle 4.5 model running over the entire Mediterranean Sea at a resolution of 1/30 degree. In some selected areas, regional scale WAM implementations (at approx. 1/60 degree resolution) are nested in the large scale-grid. The computations carried out at this level use the deep-water version of WAM. Finally, the coastal models are nested inside each regional grid. The coastal implementation is based on the SWAN cycle 2 (40.72), running at a resolution of 1/240 degrees. The coastal implementation, in the current stage of development of the MCFS, does not take into account refraction by currents and diffraction by the topography. The 


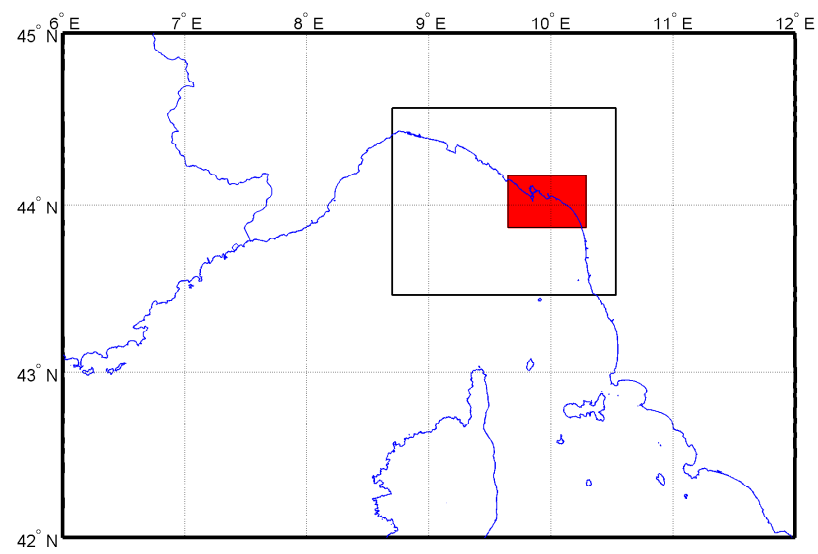

Fig. 2. Position of the regional grid (black box) and coastal grid (red box) in the Ligurian Sea.

regional areas considered in the present study are located in the Ligurian Sea, the Central Tyrrhenian Sea and the Southern Tyrrhenian Sea. The areas were selected to include both one available shallow-water buoy (in a range of $10-50 \mathrm{~m}$ depth) and a meteorological station. The bathymetry of the Mediterranean Sea was interpolated from the General Bathymetric Chart of the Ocean, the GEBCO-08, 30 arc-second grid dataset. In the regional areas the GEBCO-08 and the Hydrological Institute of the Italian Navy (IIM) regional marine coastal charts were merged. In coastal areas, where available, small-scale bathymetric data were added. In SWAN, simulations of the bottom dissipation effects were calculated using a constant friction coefficient depending on the prevailing wind sea or swell conditions. Triad wave-wave interactions were considered by means of the Lumped Triad Approximation.The saturation-based whitecapping scheme (Van der Westhuysen, 2007) was chosen for wind input and whitecapping dissipation processes. In this formulation the dissipation term is directly related to the process of wave breaking and depends on quantities that are local (i.e. not integrated on the whole spectrum) in the frequency spectrum, differing in this respect from the Komen et al. (1984) formulation. The wind input source term was adapted from the formulation proposed by Yan for wind growth (The SWAN Team, 1993; Van der Westhuysen, 2007).

\section{Results}

The MCFS system was applied to three coastal areas in the Ligurian, the Central and the Southern Tyrrhenian Sea, which were known to be affected by severe storms (Franco et al., 2004), as shown in Fig. 1. In each area, five events were selected according to the availability of nearshore buoy data and on the severity of the storms. The lists of events for each coastal zone are reported respectively in Tables 1,2 and 3. The comparisons between recorded buoy and hindcast $H_{\mathrm{S}}$
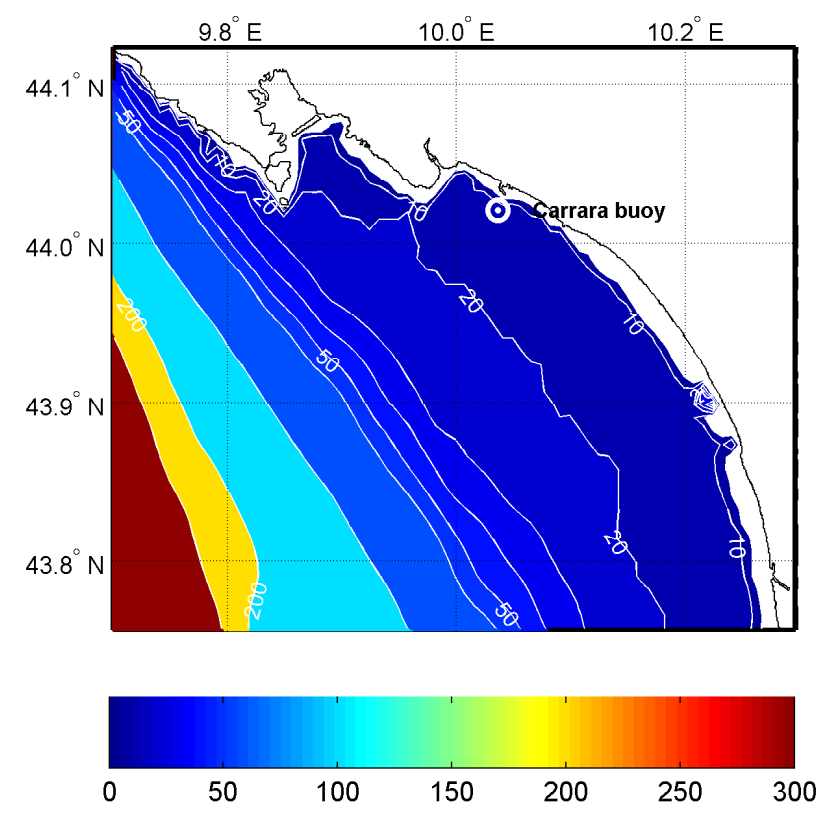

Fig. 3. Bathymetry and position of the Carrara buoy.

data are shown for each event in terms of the standard statistical operators: bias, mean absolute error (MAE), mean square error (MSE) and correlation coefficient. The comparisons between simulated and buoy $H_{\mathrm{s}}$ and peak period $\left(T_{\mathrm{p}}\right)$ for the hourly sea states of all 5 storms in each coastal area are illustrated by means of scatter diagrams. For each coastal area a single significant event is also described in terms of comparison of measured vs. hindcast (SWAN) time series of $H_{\mathrm{s}}, T_{\mathrm{p}}$, and mean wave direction (Dir). A representation of the regional-scale (WAM) contribution to the hindcast total sea in terms of swell and wind sea at the buoy position is also included. The separation between the two parts of the wave energy spectrum in WAM was calculated using a dynamic threshold based on the wave age, as described in ECMWF (2009).

\subsection{Ligurian Sea}

The positions of the regional (WAM) and coastal (SWAN) grids in the Ligurian Sea are shown in Fig. 2. The buoy used for the comparison is close to the Port of Marina di Carrara; its position, at a mooring depth of $13.5 \mathrm{~m}$, is shown in Fig. 3 . The bathymetry of the area shows a sharp gradient near the western side of the coastal grid. Inside the coastal grid the isobaths are almost parallel and the slopes decrease gently towards the shore. The statistical analysis of the comparisons between buoy data and numerical simulations are shown in Table 1 for each of the 5 events.

Generally, coastal implementations are better correlated with buoy data and have smaller BIAS than the regional model in shallow waters. The 21-30 March storm event is 
Table 1. Statistical results for the Carrara storm events

\begin{tabular}{|c|c|c|c|c|}
\hline & BIAS & MAE & MSE & corr \\
\hline \multicolumn{5}{|c|}{ 1st storm: 18-22 March 2007} \\
\hline Regional & -0.42 & 0.77 & 0.98 & 0.77 \\
\hline Coastal & -0.32 & 0.63 & 0.73 & 0.83 \\
\hline \multicolumn{5}{|c|}{ 2nd storm: 2-7 December 2007} \\
\hline Regional & -0.28 & 0.63 & 0.68 & 0.79 \\
\hline Coastal & -0.31 & 0.63 & 0.59 & 0.85 \\
\hline \multicolumn{5}{|c|}{ 3rd storm: 21-30 March 2008} \\
\hline Regional & -0.47 & 0.54 & 0.50 & 0.86 \\
\hline Coastal & -0.35 & 0.48 & 0.43 & 0.84 \\
\hline \multicolumn{5}{|c|}{ 4th storm: 29 October-2 Nov. 2008} \\
\hline Regional & -0.10 & 0.44 & 0.32 & 0.84 \\
\hline Coastal & -0.01 & 0.47 & 0.38 & 0.86 \\
\hline \multicolumn{5}{|c|}{ 5th storm: 4-8 December 2008} \\
\hline Regional & 0.11 & 0.71 & 0.76 & 0.76 \\
\hline Coastal & 0.31 & 0.56 & 0.52 & 0.86 \\
\hline
\end{tabular}

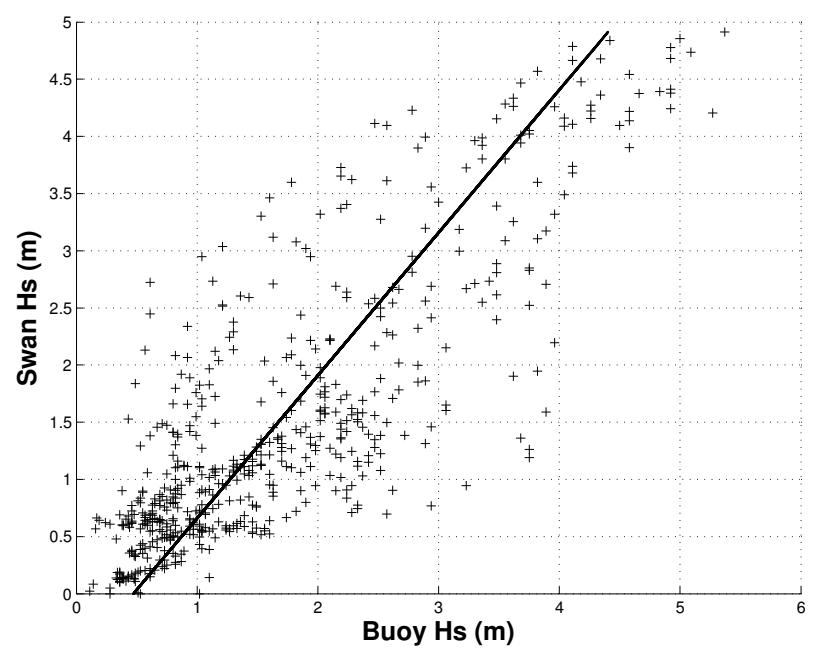

Fig. 4. Scatter diagram of buoy recorded vs. SWAN $H_{\mathrm{S}}$ at Carrara. The storm events considered in the analysis are listed in Table 1.

an exception, because during this period there was a distinct secondary maximum of $H_{\mathrm{s}}$ (not shown), which was not correctly predicted by the wave forecast. RMN wind records on the coast nearby indicate that this second peak was due to a rapid increase in wind velocity that was not correctly simulated by the meteorological model. The comparison between observations and coastal simulations of $H_{\mathrm{s}}$ for all the 5 episodes considered in the area is shown in Fig. 4.

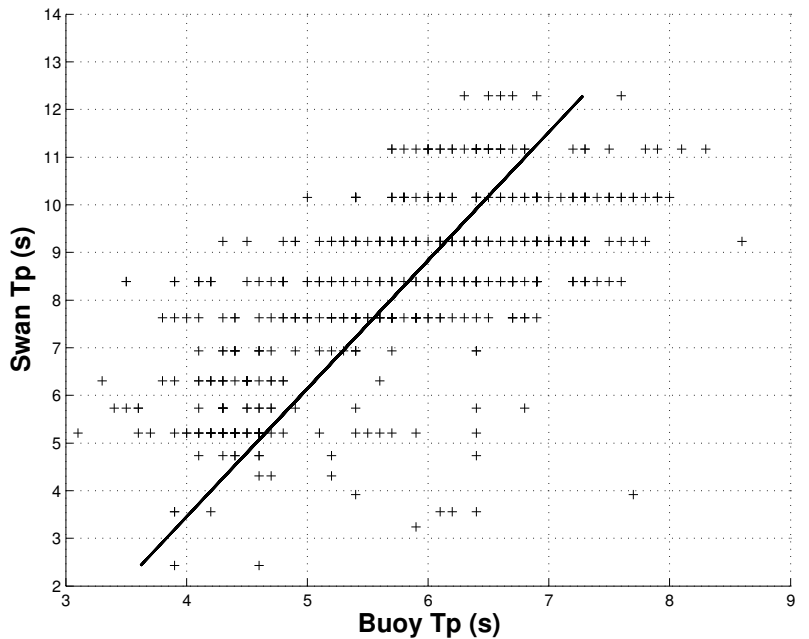

Fig. 5. Scatter diagram of buoy recorded vs. SWAN $T_{\mathrm{p}}$ at Carrara. The storm events considered in the analysis are listed in Table 1

The overall correspondence is satisfactory, in particular in the range of the highest waves. Many of the underpredicted sea states, such as those which form a cloud on the lower right side of the diagram, correspond to incorrect wind forecasts. The analysis of the scatterplot suggests that the slope of the regression line in Fig. 4 might be related to a tendency of the forecasting system to set the beginning of storm events too early. The scatter diagram of buoy vs. simulated peak pe$\operatorname{riod}\left(T_{\mathrm{p}}\right)$ at Carrara is shown in Fig. 5. In all the considered events (see also Fig. 6c), the observed $T_{\mathrm{p}}$ is clearly overpredicted by the model, even exceeding $2 \mathrm{~s}$ during the 4-8 December 2008 storm. Since it is known that SWAN typically tends to underpredict $T_{\mathrm{p}}$ (Van der Westhuysen, 2006), the above results suggest that the reproduction of storm dynamics was accurate only to a limited degree.

Given that the model $T_{\mathrm{p}}$ was bigger than the measured one, a possible explanation for the result is that at the regional scale the contribution of the swell to the total wave energy is dominant compared to that of the local wind-sea. The analysis of the WAM results at the buoy position in terms of the swell contribution to the total sea (see Fig. 6d) seems to support this conjecture. The Ligurian Sea is an area of active secondary cyclogenesis, where small (400-500 km typical radius), rapid storms develop due to the proximity of the Alpine mountain ranges (Lionello et al., 2006). If the meteorological model fails to reproduce the quick changes in wind direction associated with a small storm, the wave model incorrectly predicts both the wave age and the direction of the waves. This, in turn, could explain the presence of the dominant swell contribution. 
(a)

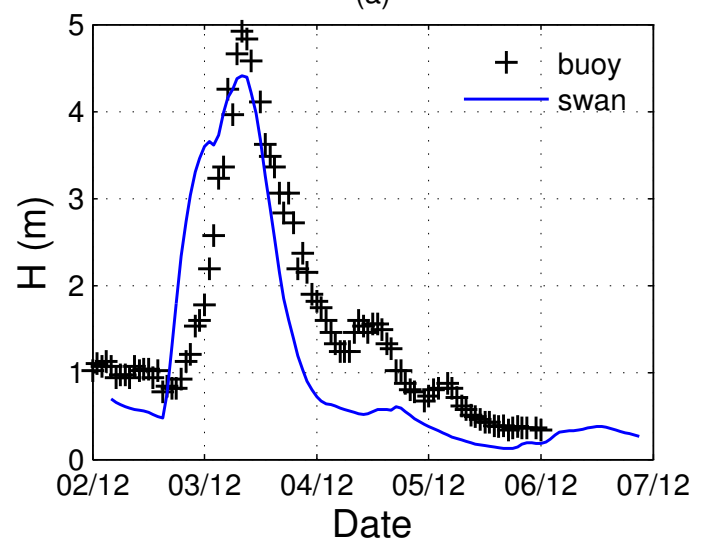

(c)

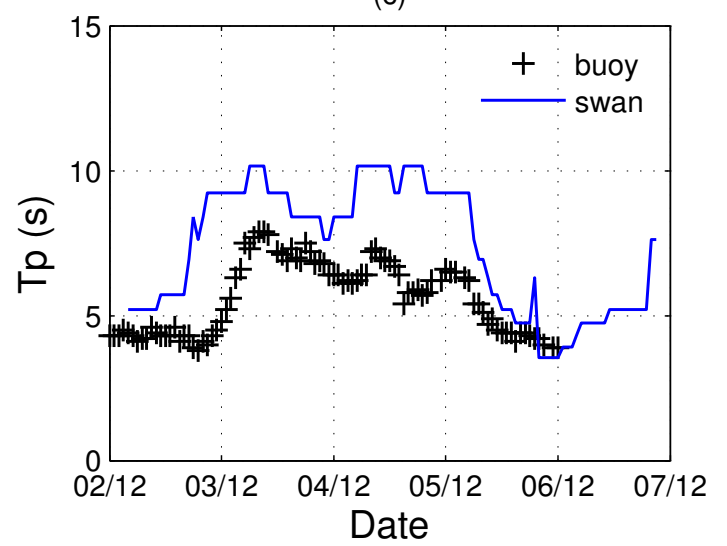

(b)

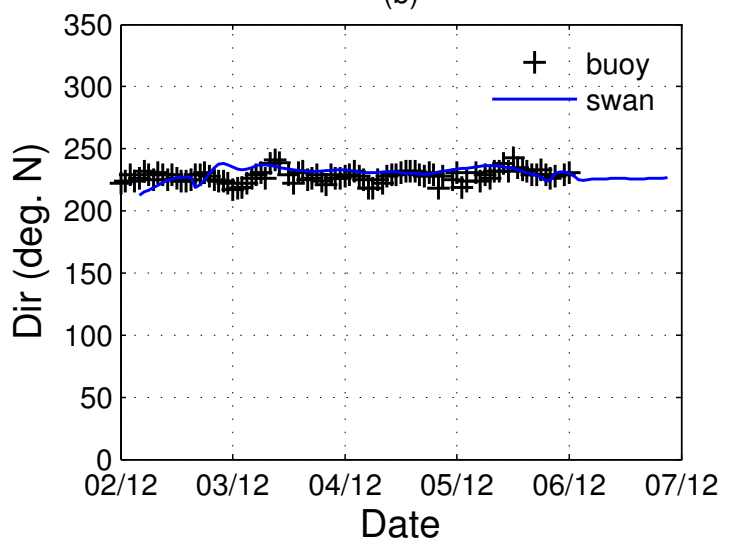

(d)

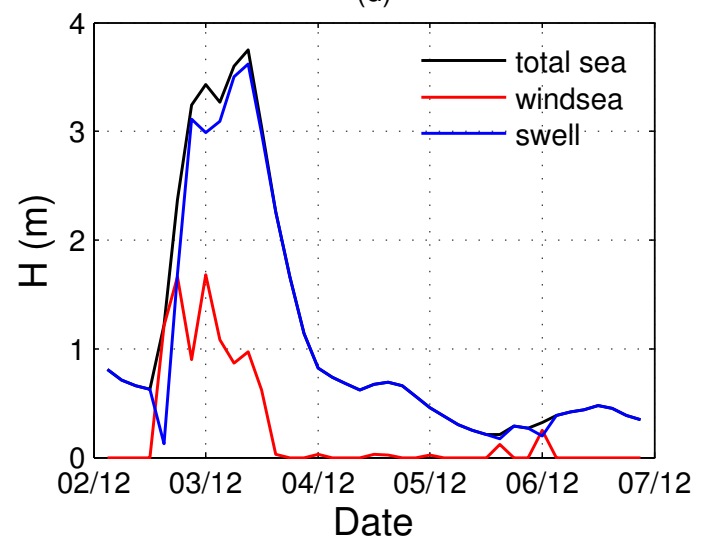

Fig. 6. Carrara, 2-7 December 2007 storm: (a) comparison of $H_{\mathrm{S}}$ SWAN vs. buoy records, (b) comparison of Dir SWAN vs. buoy records, (c) comparison of $T_{\mathrm{p}}$ SWAN vs. buoy records, (d) WAM series of wind sea, swell and total $H_{\mathrm{S}}$ out of the regional grid.

\subsection{Central Tyrrhenian Sea}

The positions of the regional and coastal grids in the Central Tyrrhenian Sea region are shown in Fig. 7. The buoy used for the comparison is located near Civitavecchia on $35 \mathrm{~m}$ water depth (Fig. 8).

At Civitavecchia location, all statistics (see Table 2) improve when passing from the regional to the coastal scale implementations, with the exception of the 1-15 June 2002 storm, for which SWAN overpredicts $H_{\mathrm{S}}$ during the peak of the storm (by $25 \%$ ).

During two of the episodes considered (27 August4 September 2001 and 2-11 November 2001), the main wave direction was steadily northeastward and the agreement with measurements was good for the entire duration of the storm. During the last storm, 2-7 February 2003, (Fig. 11a, b and c), a $180 \mathrm{deg}$. rotation of the wave direction preceeded the storm, while during the peak the direction was steady from the south west. Even though the comparisons between forecasted and recorded wind speed at Civitavecchia (not shown) were in reasonable agreement, the peak of the storm was

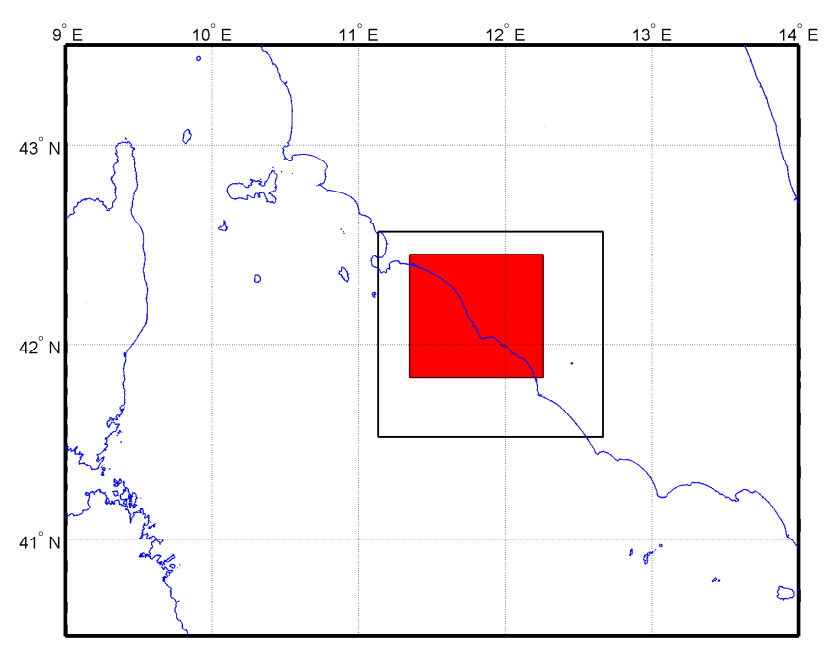

Fig. 7. Position of the regional grid (black box) and coastal grid (red box) in the Central Tyrrhenian Sea. 

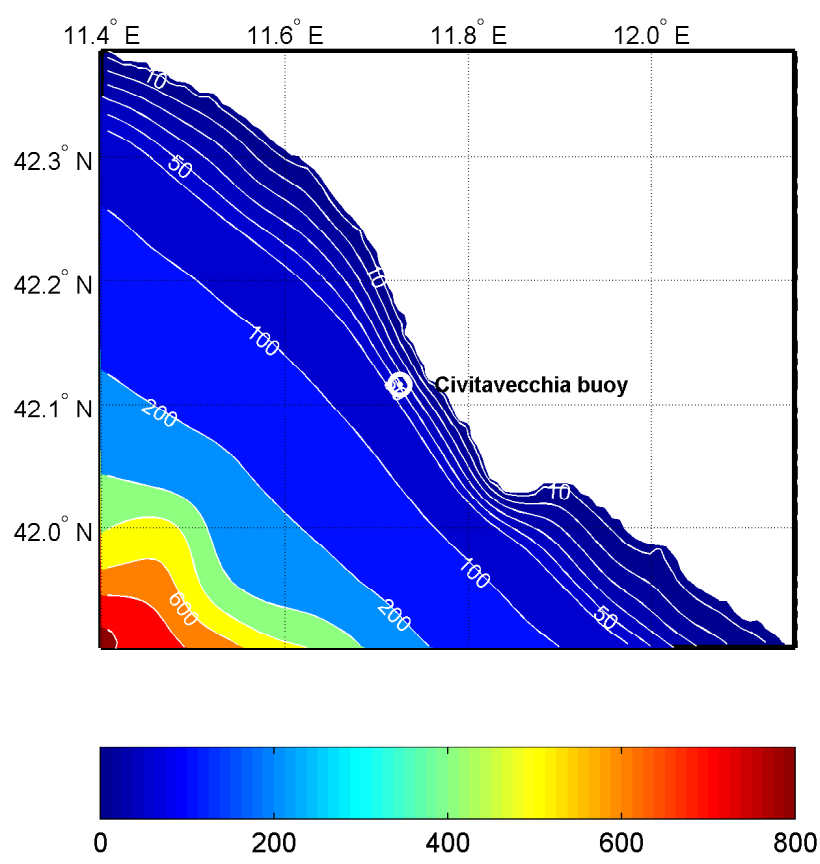

Fig. 8. Bathymetry and position of the Civitavecchia buoy.

Table 2. Statistical results for the Civitavecchia storm events.

\begin{tabular}{lcccc}
\hline & BIAS & MAE & MSE & corr \\
\hline 1st storm: 27 August-04 September 2001 \\
\hline Regional & -0.16 & 0.31 & 0.18 & 0.90 \\
Coastal & -0.03 & 0.13 & 0.07 & 0.96 \\
\hline 2nd storm: $2-11$ November 2001 & \\
\hline Regional & -0.31 & 0.32 & 0.24 & 0.85 \\
Coastal & -0.02 & 0.13 & 0.08 & 0.91 \\
\hline 3rd storm: & $1-15$ June 2002 & & \\
\hline Regional & 0.01 & 0.18 & 0.06 & 0.90 \\
Coastal & 0.13 & 0.17 & 0.15 & 0.95 \\
\hline 4th storm: & $19-27$ September 2002 & \\
\hline Regional & -0.47 & 0.52 & 0.43 & 0.87 \\
Coastal & -0.12 & 0.17 & 0.15 & 0.92 \\
\hline 5th storm: $2-7$ February 2003 & \\
\hline Regional & -0.38 & 0.46 & 0.44 & 0.88 \\
Coastal & 0.08 & 0.22 & 0.19 & 0.95 \\
\hline
\end{tabular}

overestimated by the model. Figure $11 \mathrm{~d}$ indicates that the initial part of the simulated storm was due to local wind generation.

On the contrary, since the comparison between recorded and simulated peak period (Fig. 11b) shows that in the growth stage of the storm the buoy $T_{\mathrm{p}}$ was bigger than the

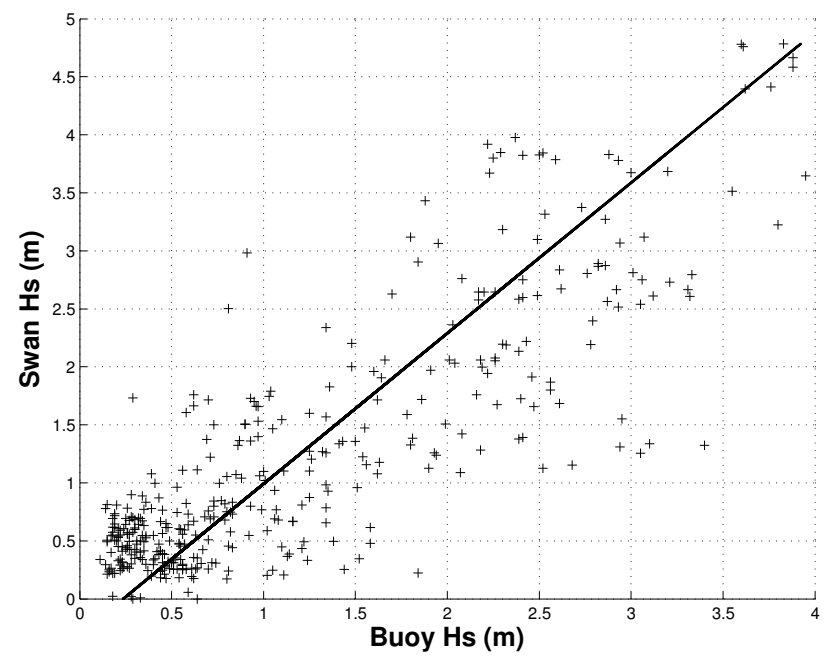

Fig. 9. Scatter diagram of buoy recorded vs. SWAN $H_{\mathrm{S}}$ at Civitavecchia. The storms considered in the analysis are listed in Table 2.

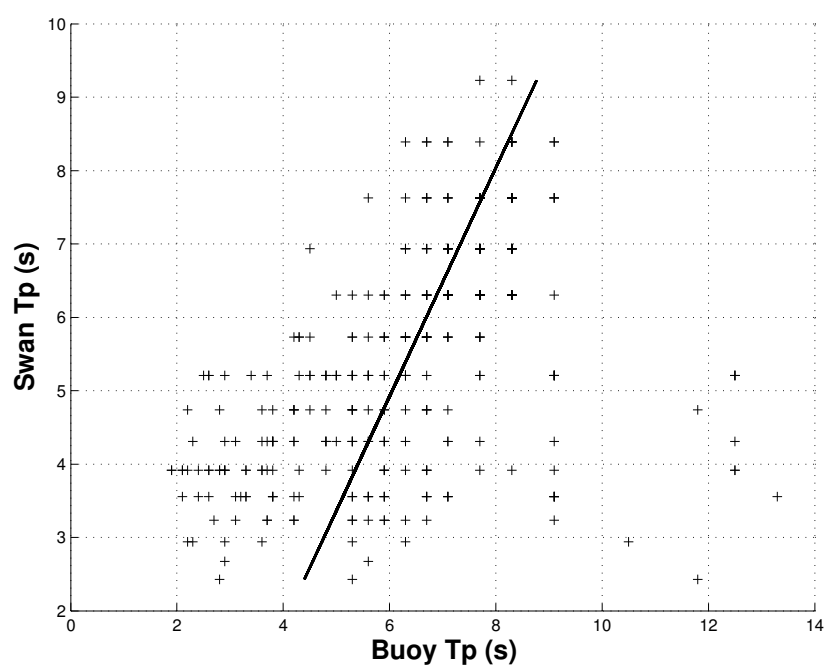

Fig. 10. Scatter diagram of buoy recorded vs. SWAN $T_{\mathrm{p}}$ at Civitavecchia. The storms considered in the analysis are listed in Table 2 .

SWAN results, it is resonable to assume that in the real storm there was an important contribution of the swell. The results seem to indicate that the model apparently failed to follow the rotation of the wind at the beginning of the storm, possibly because of the relatively large time step $(3 \mathrm{~h})$ of the wind input. The scatterplot of observed vs. simulated $H_{\mathrm{s}}$ is shown in Fig. 9. A slight tendency towards overprediction by the MCFS, indicated by the position of the maxima in the upper side of the plot, is observable. The cluster of points on the right of the picture, showing situations of definite underprediction, corresponds to an episode in which the beginning of the storm was incorrectly predicted by the meteorological forecast. In the case of Civitavecchia, too, a 
(a)

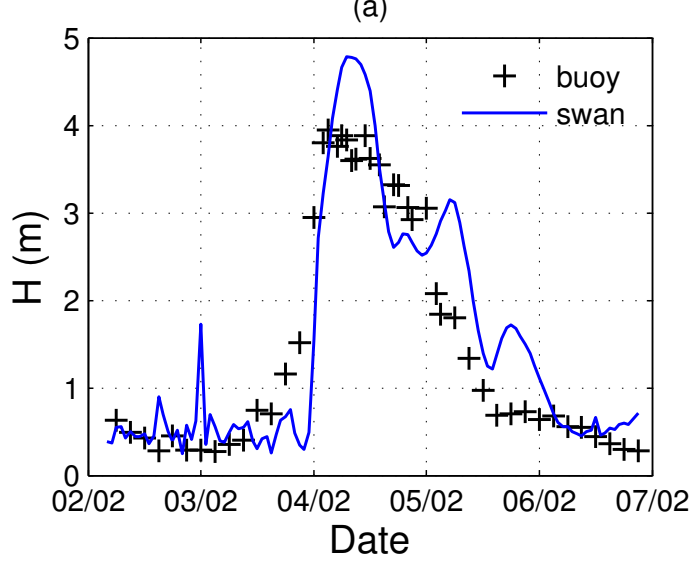

(c)

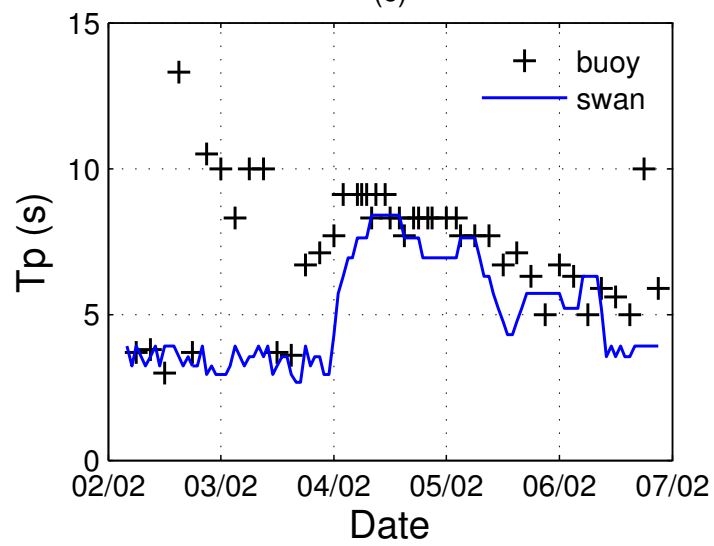

(b)

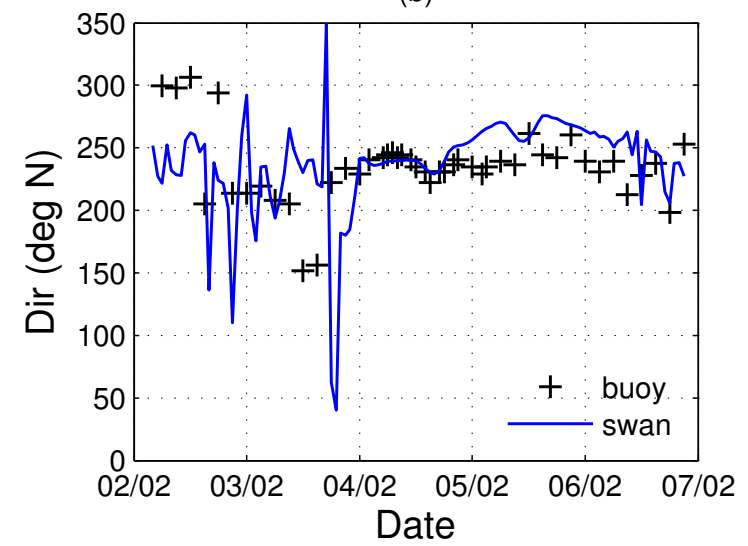

(d)

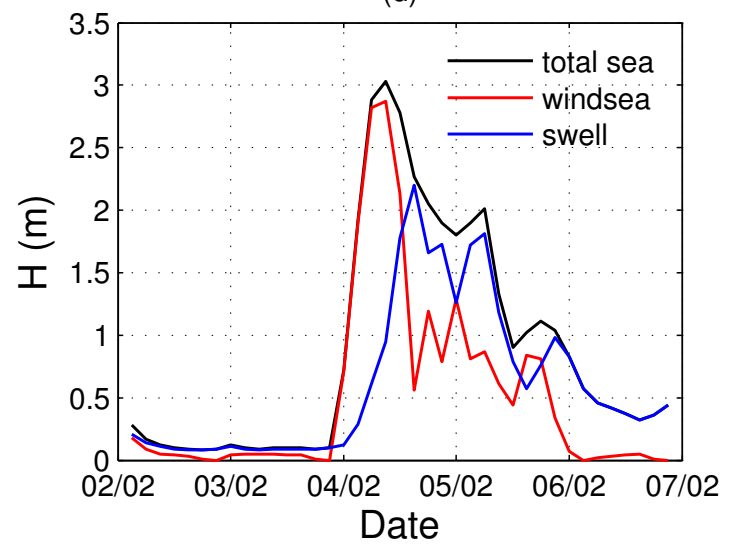

Fig. 11. Civitavecchia, 2-7 February 2003 storm: (a) comparison of SWAN vs. buoy $H_{\mathrm{s}}$, (b) comparison of SWAN vs. buoy Dir, (c) comparison of SWAN vs. buoy $T_{\mathrm{p}}$, (d) WAM series of wind sea, swell and total $H_{\mathrm{S}}$ out of the regional grid.

slight tendency to overprediction of the peak period can be observed (Fig. 10). The points on the right, lower part of the $T_{\mathrm{p}}$ scatterplot, which correspond to the first part of the time series shown in Fig. 11c, refer to a situation of calm sea $\left(H_{\mathrm{S}}<0.3 \mathrm{~m}\right)$, and hence are not related to wind waves.

\subsection{Southern Tyrrhenian Sea}

The grids considered in the Southern Tyrrhenian Sea are indicated in Fig. 12. In Fig. 13 the bathymetry and position of the buoy, moored at $50 \mathrm{~m}$ depth near Tropea are shown.

The statistics of the five case studies are shown in Table 3.

In all the considered events, there is a substantial improvement for BIAS, MSE and MAE when passing from the regional to the coastal grid. The comparison between the $H_{\mathrm{s}}$ recorded at Tropea and the MCFS simulations are shown in Fig. 14 for all 5 episodes. There is an overall correspondence between observations and forecasts, which is also visible in the comparison of the time series for the 5-13 October 2003 event (Fig. 16a). The peak periods in Fig. 16c are scattered, but there is no apparent systematic overprediction.

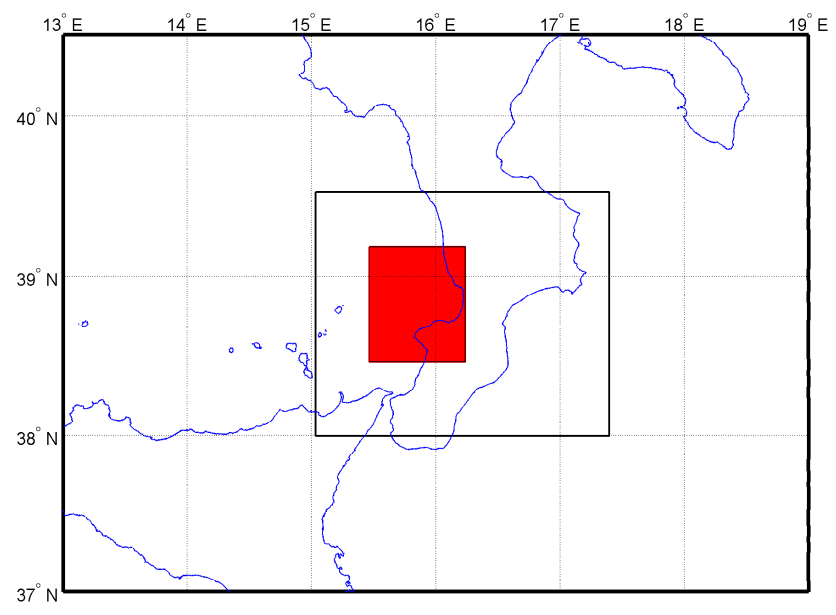

Fig. 12. Position of the regional grid (black box) and coastal grid (red box) in the Southern Tyrrhenian Sea. 

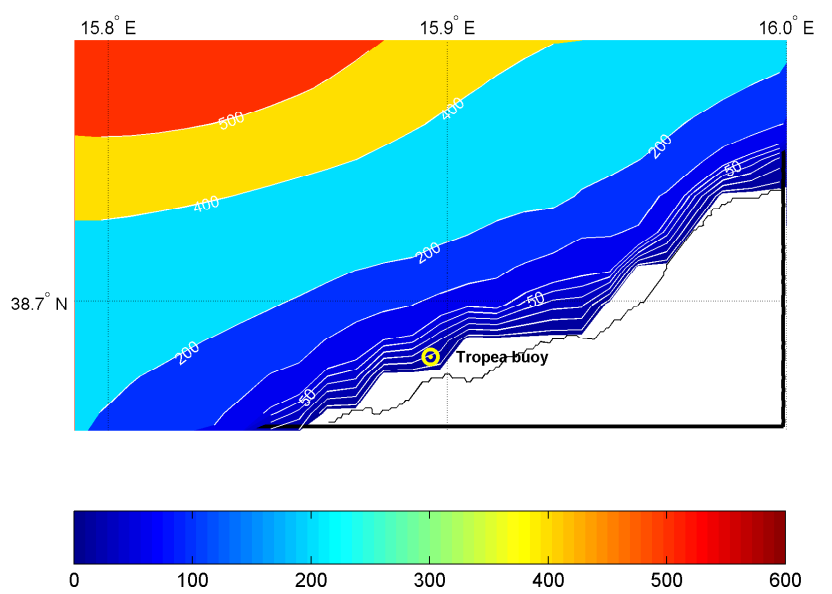

Fig. 13. Bathymetry and position of the buoy near Tropea.

Table 3. Statistical results for the Tropea storm events.

\begin{tabular}{|c|c|c|c|c|}
\hline & BIAS & MAE & MSE & corr \\
\hline \multicolumn{5}{|c|}{ 1st storm: 5-13 October 2003} \\
\hline Regional & -0.35 & 0.35 & 0.21 & 0.95 \\
\hline Coastal & -0.08 & 0.09 & 0.04 & 0.96 \\
\hline \multicolumn{5}{|c|}{ 2nd storm: 14-21 December 2003} \\
\hline Regional & -0.16 & 0.20 & 0.07 & 0.96 \\
\hline Coastal & 0.02 & 0.08 & 0.05 & 0.96 \\
\hline \multicolumn{5}{|c|}{ 3rd storm: 19-25 January 2004} \\
\hline Regional & -0.22 & 0.22 & 0.10 & 0.97 \\
\hline Coastal & -0.02 & 0.07 & 0.03 & 0.96 \\
\hline \multicolumn{5}{|c|}{ 4th storm: 5-10 March 2004} \\
\hline Regional & -0.51 & 0.58 & 0.41 & 0.83 \\
\hline Coastal & -0.08 & 0.14 & 0.10 & 0.91 \\
\hline \multicolumn{5}{|c|}{ 5th storm: 15-25 April 2004} \\
\hline Regional & -0.10 & 0.13 & 0.04 & 0.97 \\
\hline Coastal & 0.01 & 0.05 & 0.02 & 0.97 \\
\hline
\end{tabular}

\section{Conclusions}

This study presents the results of 15 key-studies ( 5 events for each of the three different coastal areas) selected in order to determine the reliability of a high-resolution coastal wave forecasting system (MCFS) in the Ligurian, the Central Tyrrhenian and the Southern Tyrrhenian Sea. Although the selected set of episodes does not represent all possible situations, we can conclude that when the meteorological forecasts were accurate, the MCFS was able to give satisfactory results in complex coastal areas with water depths between 13 and $50 \mathrm{~m}$. In shallow water the coastal model gave better

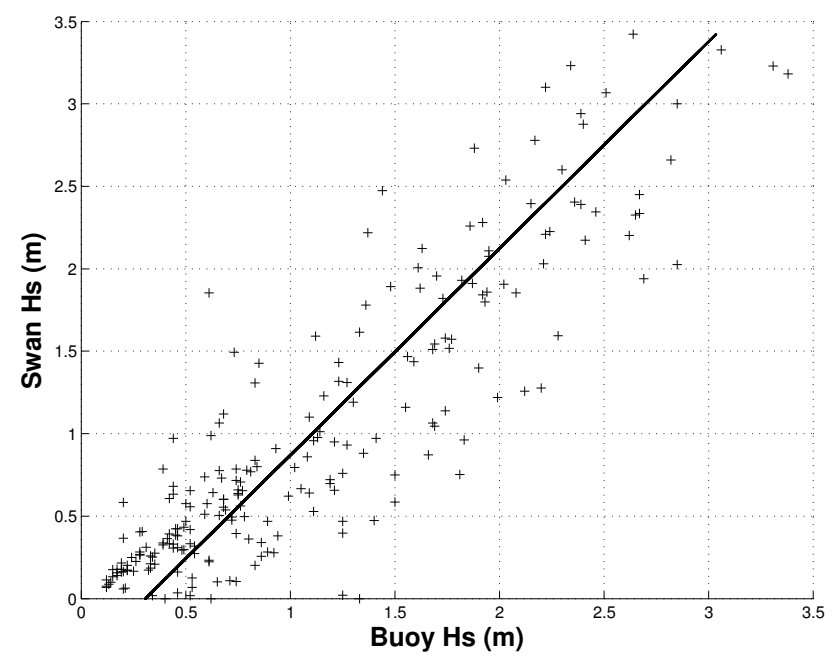

Fig. 14. Scatter diagram of buoy recorded vs. SWAN $H_{\mathrm{S}}$ at Tropea. The storms considered in the analysis are listed in Table 3.

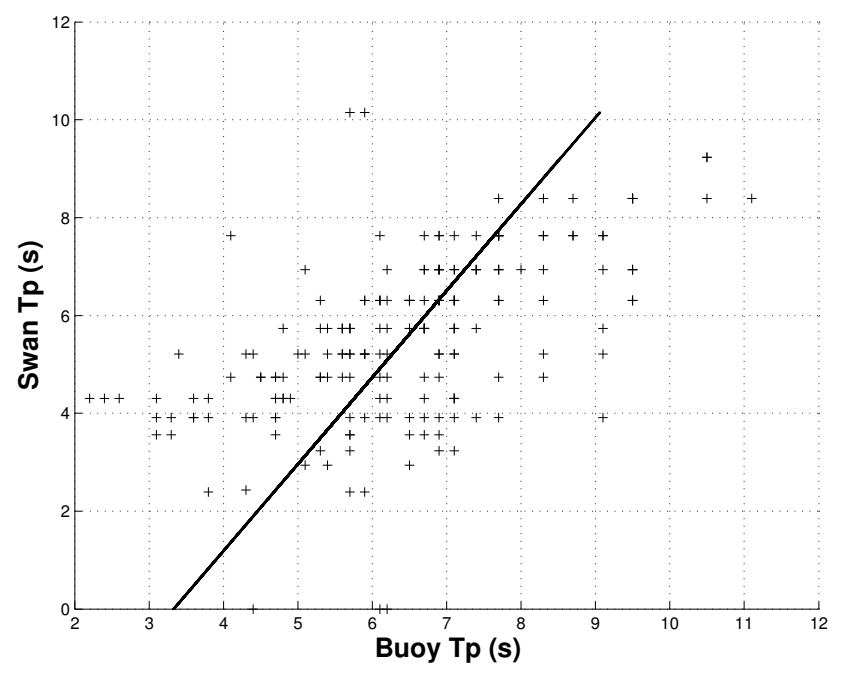

Fig. 15. Scatter diagram of buoy recorded vs. SWAN $T_{\mathrm{p}}$ at Tropea. The storms considered in the analysis are listed in Table 3 .

results than the regional model, mostly due to a more accurate representation of the bathymetry. This was gratifying as the primary benefit of the use of the coastal model is that it should realistically reproduce the effect of shoaling and define more accurately the surf zones. It was observed that the scheme for wind input/whitecapping (Van der Westhyuisen, 2007), recently introduced into SWAN, performed well in finite and shallow water depth. On the other hand, since the wind input/whitecapping dissipation scheme is very effective in transforming local wind stress into wind wave growth, when the forecasts provide an excessive wind speed in the regional and coastal areas, this can result in a neat overprediction of the peak of the storm. The degree of accuracy of the wind field was the main limit found in the case studies. 
(a)

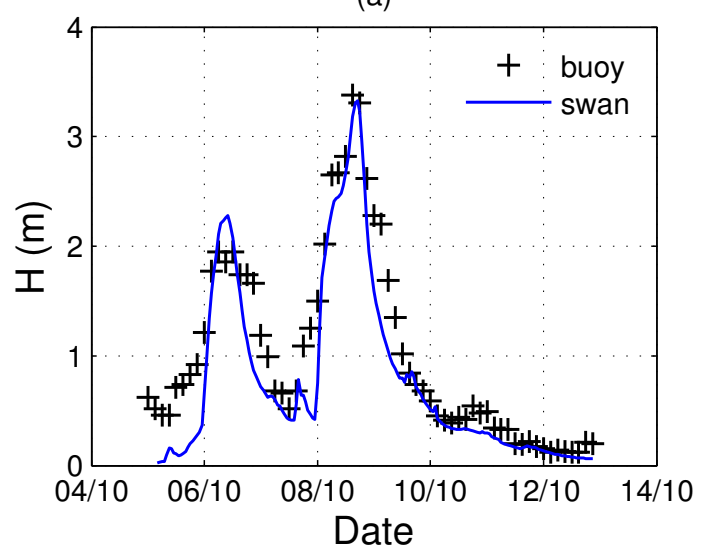

(c)

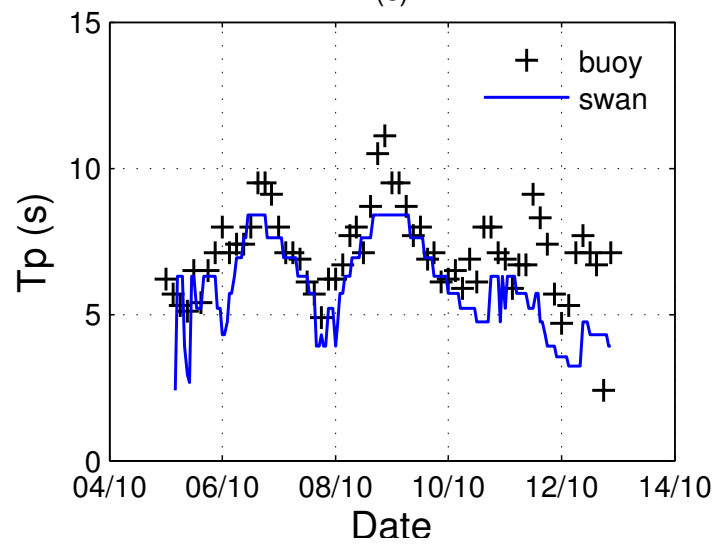

(b)

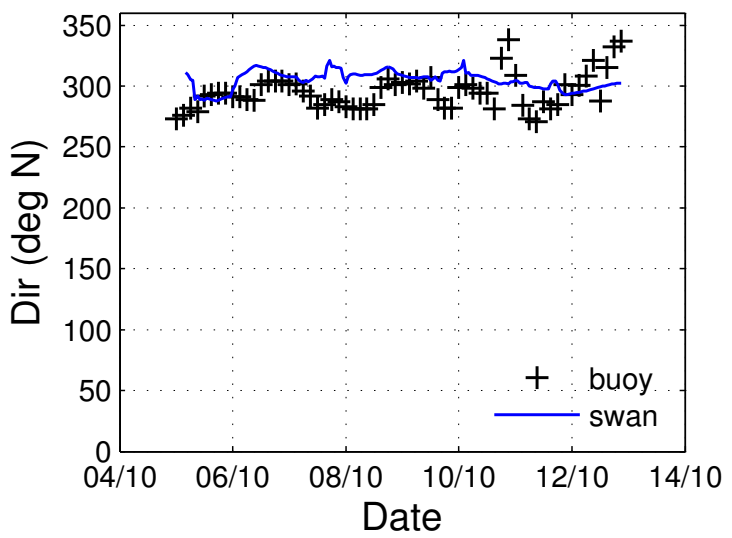

(d)

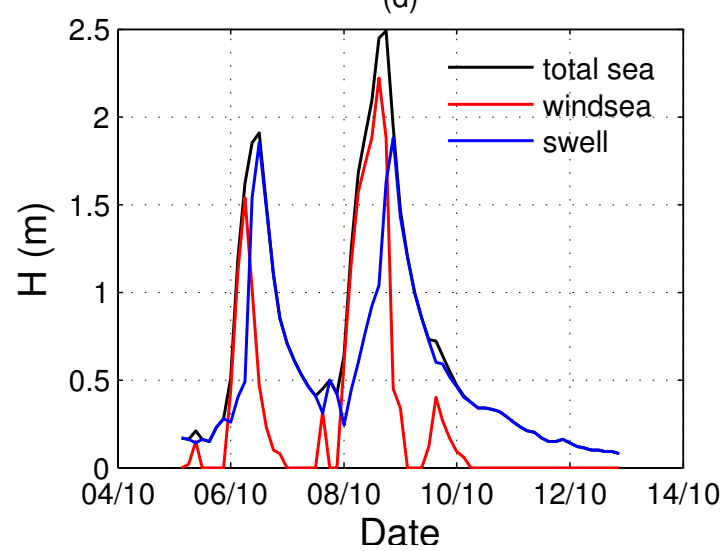

Fig. 16. Tropea, 5-13 October 2003 storm: (a) comparison of $H_{\mathrm{S}}$ SWAN vs. buoy records, (b) comparison of Dir SWAN vs. buoy records, (c) comparison of $T_{\mathrm{p}}$ SWAN vs. buoy records, (d) WAM series of wind sea, swell and total $H_{\mathrm{s}}$ out of the regional grid.

While the results were satisfactory in the Southern Tyrrhenian Sea, in the Ligurian and in the Central Tyrrhenian Sea, some minor events were missed and the $T_{\mathrm{p}}$ was often overpredicted. In order to deal with rapidly moving storms in the Northern Tyrrhenian and in the Ligurian Sea where the direction of the wind rotates and storms develop in a matter of hours, some benefit can be expected from an enhanced resolution of the wind field generated by the LAM. In order to give a better response in the simulation of the turning of the wind, an hourly wind input appears necessary.

Acknowledgements. The authors thank the Port Authority of Marina di Carrara ("Sistema di monitoraggio meteomarino del Porto di Carrara"), the Regione Calabria, and ENEL for making their data available. The authors are indebted to Ing. Andrea Valentini of ARPA-ER for his many useful suggestions concerning the use of SWAN. Our thanks to Sara Morucci of ISPRA for her analysis of bathymetric data. This study would not have been possible without the work of Heinz Guenther and Arno Behrens of GKSS who maintain the parallel version of WAM and kindly made it available to us. Credits must also be given to the WISE community and in particular to Luigi Cavaleri and Luciana Bertotti for always being supportive and helpful.
Edited by: K. Lagouvardos

Reviewed by: V. Polnikov and two other anonymous referees

\section{References}

Accadia, C., Mariani, S., Casaioli, M., Lavagnini, A., and Speranza, A.: Sensitivity of Precipitation Forecast Skill Scores to Bilinear Interpolation and a Simple Nearest-Neighbor Average Method on High-Resolution Verification Grids, Weather Forecast., 18, 918-932, 2002.

Buzzi, A., Fantini, M., Malguzzi, P., and Nerozzi, F.: Validation of a limited area model in cases of Mediterranean cyclogenesis: surface fields and precipitation scores., Meteorol. Atmos. Phys., 53, 137-153, 1994.

Bertotti, L. and Cavaleri, L.: On the influence of resolution on wave modeled results in the Mediterranean Sea, Il Nuovo Cimento, 29, 9 pp., doi:10.1393/ncc/i2005-10210-6, 2006.

Bertotti, L. and Cavaleri, L.: Large and small scale wave forecast in the Mediterranean Sea, Nat. Hazards Earth Syst. Sci., 9, 779788, doi:10.5194/nhess-9-779-2009, 2009.

Booij, N., Ris, R. C., and Holthuijsen, L. H.: A third-generation wave model for coastal regions, J. Geo. Res., 104, 7649-7666, 1999 
Cavaleri, L. and Sclavo, M.: The calibration of wind and wave model data in the Mediterranean Sea, Coast. Eng., 53, 613-627, 2006.

ECMWF: ECMWF WAVE MODEL, IFS Documentation, part VII - Cy33r1 Operational implementation, 2009.

Franco, L., Piscopia, R., Corsini, S., and Inghilesi, R.: L'Atlante delle onde nei mari italiani - Italian Wave Atlas, Full Final Report, University of Roma TRE - APAT, 2004

Holthuijsen, L. H.: Waves in Oceanic and Coastal Waters, CUP, 2007.

Holthuijsen, L. H., Booji, N., and Bertotti, L.: The propagation of wind errors through ocean wave hind casts, J. Offshore Mech. Arct. Eng., 118, 184-189, 1996.

Janssen, P. A. E. M.: The Interaction of Ocean Waves and Wind, CUP, 2004.

Janssen, P. A. E. M.: Progress in ocean wave forecasting, J. Comput. Phys., 227, 3572-3594, 2008.

Komen, G. J., Hasselmann, S., and Hasselmann, K.: On the Existence of a Fully Developed Wind-Sea Spectrum, J. Phys. Ocean., 14, 1271-1285, 1984.

Komen, G. J., Cavaleri, L., Donelan, M., Hasselmann, K., Hasselmann, S., and Janssen, P. A. E. M.: Dynamics and Modeling of Ocean Waves, Cambridge University Press, 1994.
Lavrenov, I. V.: Wind Waves in Oceans - Dynamics and Numerical Simulations, Springer, 2003.

Lagouvardos, K., Kotroni, V., Koussis, A., and Feidas, H.: The Meteorological Model BOLAM at the National Observatory of Athens: Assessment of Two-Year Operational Use, J. Appl. Met., 42, 1667-1678, 2003.

Lionello, P., Malanotte-Rizzoli, P., and Boscolo, R.: Mediterranean Climate Variability, Elsevier, Chapter 6, 325-372, 2006.

Miles, J. W.: On the generation of surface waves by shear flow, J. Fluid Mech., 3, 185-204, 1957.

Phillips, O. M.: On the generation of waves by turbulent wind, J. Fluid. Mech., 2, 417-445, 1957.

Polnikov, V. G., Dymov, V. I., Pasechnik, T. A., Lavrenov, I. V., Abuzyarov, Z. K., and Sannasiraj, S. A.: Testing and verifying the wind wave model with an optimized source function, Oceanology, 48, 7-14, 2008.

The SWAN Team: SWAN Technical Manual, SWAN Cycle III version 40.81, Delft University of Technology, 1993.

The WISE Group: Wave Modeling - The State of the Art, Progress in Oceanography, 75, 603-674, 2007.

Van der Westhuysen, A. J., Zijlema, M., and Battjes, J. A.: Nonlinear saturation based white capping dissipation in SWAN for deep and shallow water, Coast. Eng., 54, 151-170, 2007. 